\title{
Influence of Aging Time on the Mechanical Properties and Bendability of 2A12 Aluminium Alloy
}

\author{
Ling-Yun ZHANG ${ }^{a}$, Gui-Bo WAN $^{b}$, Samuel NGUGI ${ }^{c}$, Yi-Pan ZENG ${ }^{d}$
}

Key Lab of Fundamental Science for National Defense of Aeronautical Digital Manufacturing

Process, Shenyang Aerospace University, Shenyang, 110136, China

azhangly79@163.com, bwanguibo1026@163.com, '1397275003@qq.com, dzengyp_aero@163.com

Keywords: Aluminum Alloy, Sheet, Mechanical Properties, 2A12, Heat Treatment, Aging Time.

\begin{abstract}
In this paper, the mechanical and forming properties of $2 \mathrm{~A} 12$ aluminium alloy sheet were determined by using the uniaxial tensile test, including the yield stress $\sigma_{s}$, the ultimate tensile stress $\sigma_{b}$, the strain hardening exponent $n$, the strain ratio $r$, the elastic modulus $E$ and the elongation at fracture point $\delta_{\mathrm{f}}$. The specimen used in all the experiments were heat-treated by asquenching and then age-hardened at various aging times. The minimum bending radius is also evaluated using a series of rubber-forming processes.
\end{abstract}

\section{Introduction}

Although precipitation or aging hardening phenomenon of aluminium alloys was discovered, by German metallurgist Alfred Wilm, over 100 years ago it is still not fully understood and further experiments are still being held all over the world. There is no mathematical formula or any such tool that exactly predicts the influence of aging on the mechanical properties of these alloys.

In recent years, most of the research on the influence of aging time in metallurgy focuse on the following areas:

-Peak-aging conditions

-Hardening

- Anisotropy

- Formability

- Microstructural investigation

The peak aging time is the time after quenching at which a materials mechanical properties are maximum. It however varies with temperature as found in [1] that the peak aged state of 6061-O alloy at 200c was 600 [2] found that for 6061 aluminium alloy peak aging achieved after $5 \mathrm{~h}$ at $433 \mathrm{k}$ and after $48 \mathrm{~h}$ at $373 \mathrm{k}$.

It has generally been observed that strain hardening behavior varies regularly with different aging temperatures [1] observed that for 6061-O alloy the strain hardening rate decreases substantially with increasing aging time. Precipitation hardening is also investigated [3] and observed that the coarsening of precipitates causes decrease in hardness after forming at $190 \mathrm{c}$ for about $6 \mathrm{~h}$. They conclude there is a little difference between mechanical properties of the specimens under creep forming and conventional ageing [4] observe that precipitation hardening induces anisotropy. Generally natural ageing has a negative effect on hardening.

It is observed [1] that anisotropy in the rolling direction decreased while that in the transverse direction increased with aging time. It is also observed [4] that the precipitation hardening induces anisotropy. In [3] the anisotropic behavior of 7075 aluminium alloy sheets is studied after annealing at different temperatures. Heat treatable alloys are seen to be highly anisotropic.

In [1] it is observed that formability decreases with increase in aging time. In [4] precipitation hardening affects formability of $\mathrm{Al} 2024$ sheets it is found that formability for age-hardened sheets was best in plane strain conditions than all other conditions. In [3] it is observed that springback decreases with increasing the time and temperature. It is observed that formability of $7075 \mathrm{Al}$ alloy could be improved by annealing the sheets at temperature ranges of 350-400c. 


\section{Materials and Experimental Procedure}

2A12 alloy in the form of $1 \mathrm{~mm}$ thick sheets was used. The chemical composition is as in Table 1. Part of the text specimens as shown in figure 1 and the scheme as shown in figure 2 . Tensile test specimens were prepared following the national standard of China (Metallic materials-Tensile testing-part 1: Method of testing at room temperature). All the testing procedures were performed by SANS CMT-4000 series machine, as shown in figure 3. The specimen were cut at 0 and 45 and 90 degrees with the rolling directions and had 10,20,30,40,50,60,120,180,480 minutes of aging time, respectively.

Tab.1 The chemical composition of 2A12 alloy

\begin{tabular}{|c|c|c|c|c|c|c|c|c|c|c|c|}
\hline Element & $\mathrm{Al}$ & $\mathrm{Cr}$ & $\mathrm{Cu}$ & $\mathrm{Fe}$ & $\mathrm{Mg}$ & Mn & $\mathrm{Si}$ & $\mathrm{Ti}$ & $\mathrm{Zn}$ & $\begin{array}{l}\text { Other } \\
\text { element }\end{array}$ & $\begin{array}{l}\text { Other } \\
\text { total }\end{array}$ \\
\hline $\mathrm{Wt} \%$ & $\begin{array}{l}90.7- \\
94.7\end{array}$ & $\begin{array}{c}\operatorname{Max} \\
0.1\end{array}$ & $\begin{array}{l}3.8- \\
4.9\end{array}$ & $\begin{array}{l}\operatorname{Max} \\
0.5\end{array}$ & $\begin{array}{l}1.2- \\
1.8\end{array}$ & $\begin{array}{l}0.3- \\
0.9\end{array}$ & $\begin{array}{l}\text { Max } \\
0.5\end{array}$ & $\begin{array}{l}\text { Max } \\
0.15\end{array}$ & $\begin{array}{l}\text { Max } \\
0.25\end{array}$ & $\begin{array}{l}\operatorname{Max} \\
0.05\end{array}$ & $\begin{array}{l}\text { Max } \\
0.15\end{array}$ \\
\hline
\end{tabular}

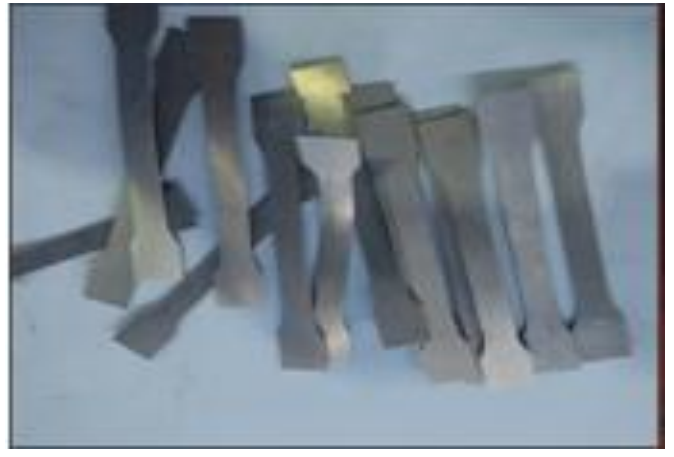

Fig. 1 Uniaxial tensile test pieces

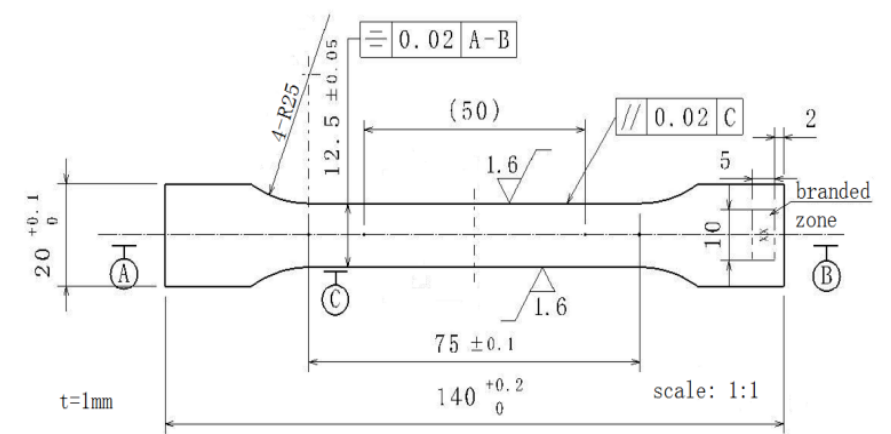

Fig. 2 The scheme of tensile test specimen
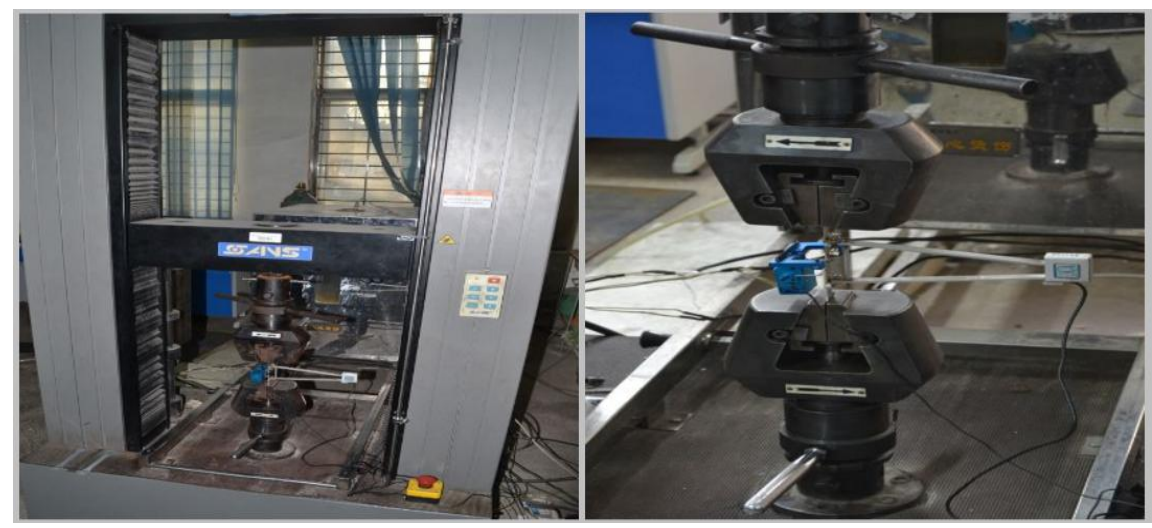

Fig. 3 SANS CMT-4000 series machine

\section{Results and Discussion}

The properties obtained were the yield stress, ultimate tensile stress, strain hardening exponent, strain ratio and elongation at fracture point. They were generally observed to vary regularly i.e. Maximum strength i.e peak ultimate tensile stress was obtained after 8 hours of aging as well as the yield stress for both rolling directions as $415 \mathrm{MPa}$ and $265 \mathrm{MPa}$ as in figures 4 and 5 respectively. After 8 hours of aging for both properties and rolling directions the values are similar indicating that beyond 8 hours of aging the rolling direction ceases to influence this property.

Peak strain hardening exponent value was obtained after 10 minutes of aging for both rolling directions as in figure 6 . The difference between the two rolling directions was slight with the 45 degree rolling direction having more strain hardening exponent with the peak value being 0.25. After 8 hours of aging the strain hardening exponent value is the same for both rolling directions. 


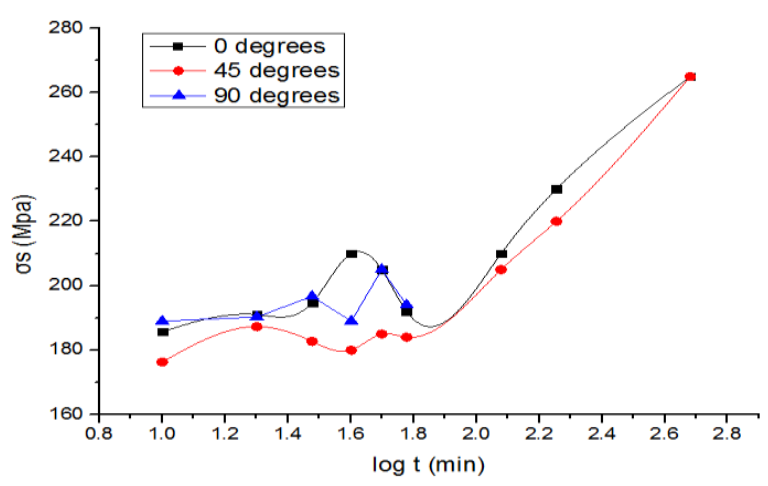

Fig. $4 \sigma_{s}$ for various $\log \mathrm{t}$

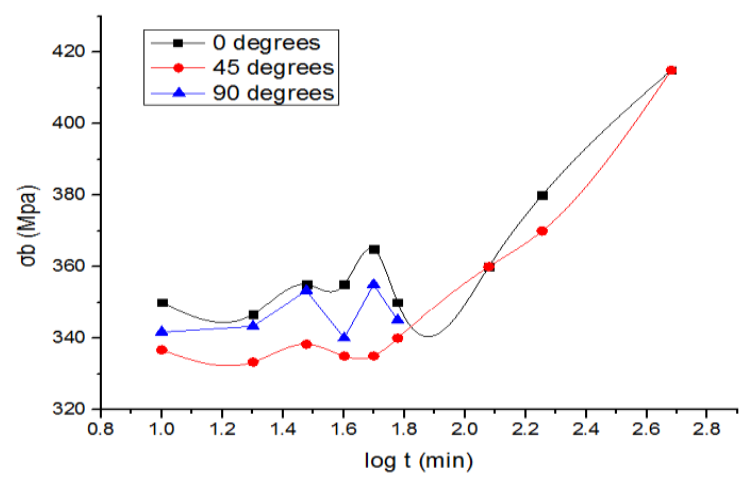

Fig. $5 \sigma_{\mathrm{b}}$ for various $\log \mathrm{t}$

Peak strain ratio value was obtained after 1 hour of aging as 1.18 as in figure 7 . The 45 degree rolling direction showed greater anisotropy than the 0 degree rolling direction. As in the other properties the strain hardening exponent value is the same for both directions after 8 hours of aging. As shown in figure 8 and 9 respectively, the average $r$ value and earing tendency are also shown to vary regularly. These were calculated as follows:

$$
\begin{aligned}
& \mathrm{r}_{\mathrm{m}}=\left(\mathrm{r}_{0}+2 \mathrm{r}_{45}+\mathrm{r}_{90}\right) / 4 \\
& \Delta \mathrm{r}=\left(\mathrm{r}_{0}-2 \mathrm{r}_{45}+\mathrm{r}_{90}\right) / 2
\end{aligned}
$$

Where

$$
\begin{aligned}
& \mathrm{r}_{\mathrm{m}}=\text { average } \mathrm{r} \text { value } \\
& \Delta \mathrm{r}=\text { plannar anisotropy }
\end{aligned}
$$

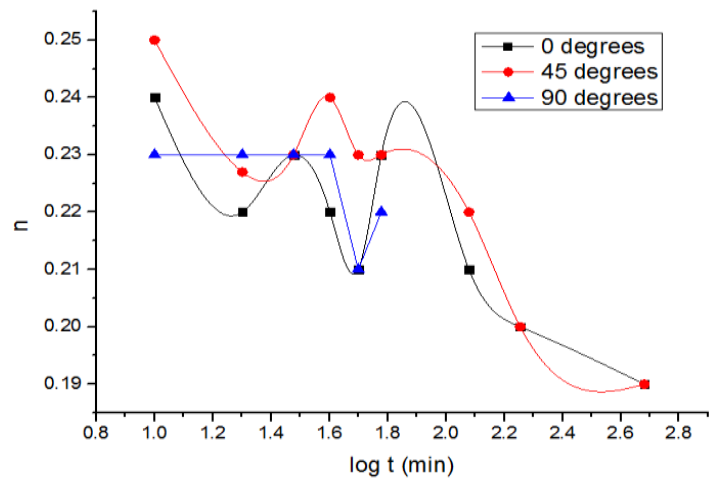

Fig. $6 \mathrm{n}$ for various $\log \mathrm{t}$

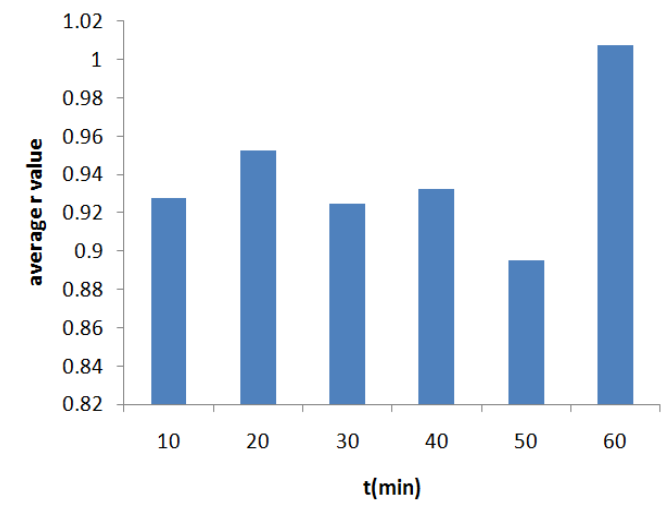

Fig. 8 Average $r$ value vs. aging time

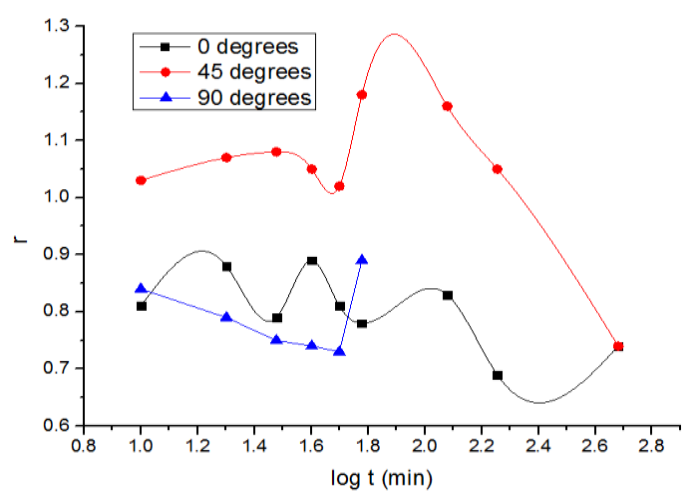

Fig. $7 \mathrm{r}$ for various $\log \mathrm{t}$

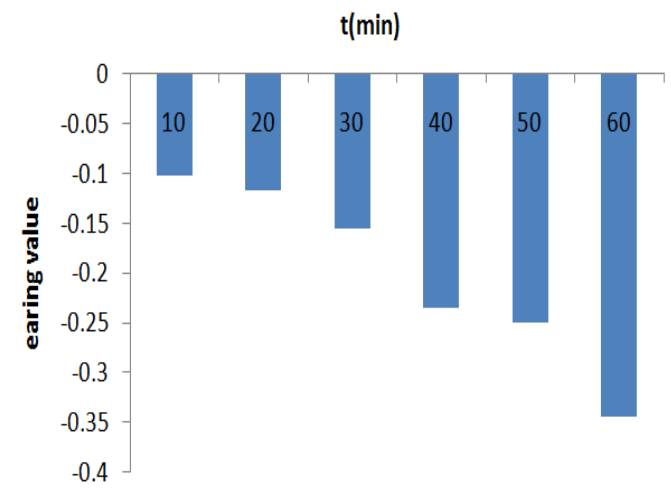

Fig. 9 Earing tendency vs. aging time 


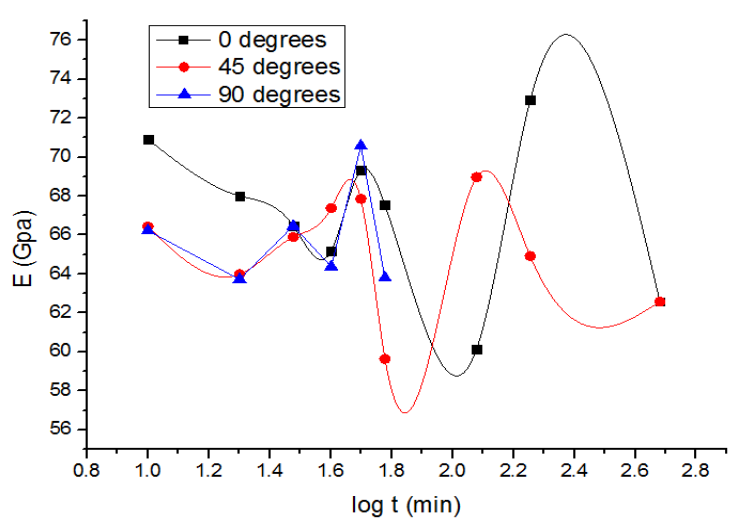

Fig. $10 \mathrm{E}$ for various $\log \mathrm{t}$

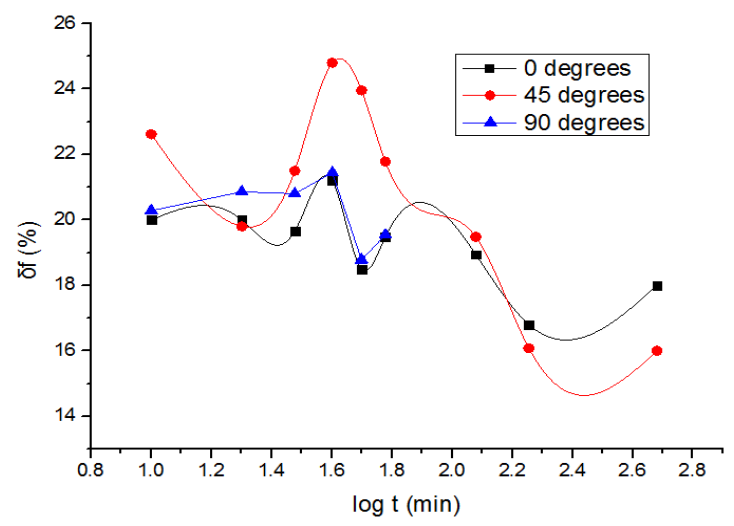

Fig. $11 \delta_{\mathrm{f}}$ for various $\log \mathrm{t}$

The elastic modulus was seen to be fairly constant as per figure 10 although a peak value was obtained after 3 hours of aging as $72.92 \mathrm{Gpa}$ for 0 degree rolling direction. The value after 8 hours of aging was the same for both rolling directions.

As shown in figure 11, the elongation at fracture i.e total tensile elongation reached a peak value of $24.8 \%$ after 40 minutes of aging. The 45 degree rolling direction has larger elongation than the 0 degree rolling direction.

The bendability of 2A12 alloy was evaluated in terms of minimum bend radius for the rubber forming process and was found to be $1.4 \mathrm{~mm}$. The relative minimum bend ratio was then evaluated using the obtained total tensile elongation data. The bend factor or relative minimum bend radius was calculated using the following equations:

$$
\begin{aligned}
& \mathrm{F}=[(100 / e)-1] / 2 \\
& \mathrm{~F}=[(100 / 0.85 \text { e typical })-1] / 2
\end{aligned}
$$

The relative minimum bend ratio varied as per figures 12 and 13 . For the 0 degree rolling direction it increased gradually and proportionately. For the 45 degree rolling direction it decreases with aging time then increases after 40 minutes of aging.

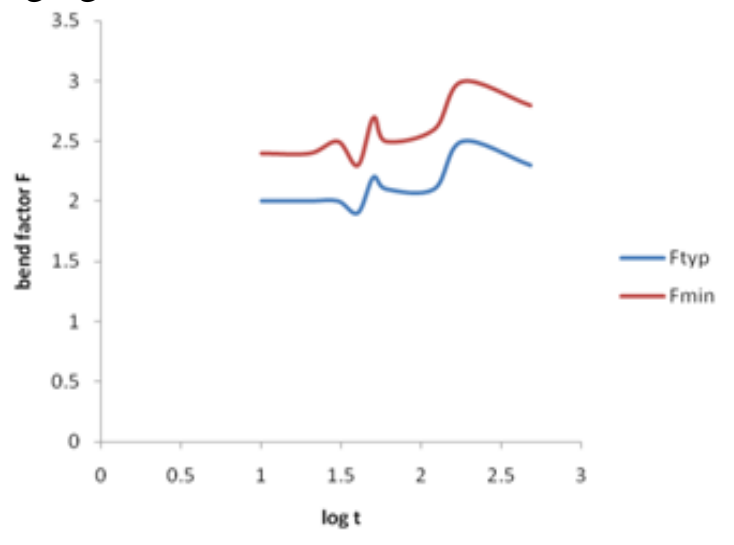

Fig. 12 Bend factor vs. aging time for 0 degree rolling direction

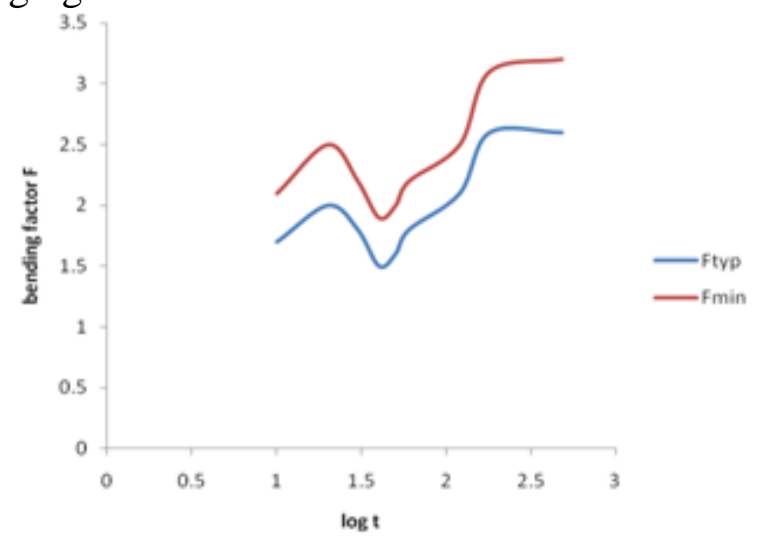

Fig. 13 Bend factor vs. aging time for 45 degree rolling direction

\section{Conclusions}

The mechanical properties of 2A12 aluminium alloy were observed to vary regularly with aging however general trends are observed: both $\sigma_{s}$ and $\sigma_{b}$ increase with aging, The strain hardening exponent reduces with aging but very gradually, The strain ratio value decreases with aging, The 
elastic modulus is fairly constant with aging, Elongation decreases with aging, Peak hardening is obtained at the 10 minutes aging condition. Peak strength is obtained after 8 hours of aging. 2 A12 alloy achieves its over-aged state beyond 8 hours of aging. The 45 degree rolling direction shows better response to aging treatment.

The bendability of the alloy 2A12 decreases with increasing aging time as per corresponding elongation values and it's more bendable in the 0 degree rolling direction.

\section{References}

[1]Fahrettin Ozturk, "Effects of aging parameters on formability of 6061-O alloy", journal of materials and design vol 31, pp 487-4852, 2010.

[2] Mohammad Reza Rezaei, "Effects of ARB and ageing processes on mechanical properties and microstructure of 6061 aluminum alloy", journal of material processing technology vol 211, pp 1184-1190, 2011.

[3] H.R. Shahverdia, "Effects of time and temperature on the creep forming of 7075 aluminum alloy Springback and mechanical properties", journal of material science and engineering vol A 528, pp 8795-8799, 2011.

[4] Charles K.S. Moy, "Influence of heat treatment on the microstructure, texture and formability of 2024 aluminium alloy", journal of materials science and engineering vol A552, pp48-60, 2012. 